\title{
Synthesis of photoreactive solvent-free acrylic pressure-sensitive adhesives in the recovered system
}

\author{
${ }^{1}$ Roland Milker, ${ }^{2}$ Zbigniew Czech, ${ }^{2}$ Marta Wesołowska \\ ${ }^{1}$ ChemCycle Bitterfeld GmbH, 06758 Wolfen, Germany \\ ${ }^{2}$ Szczecin University of Technology, Institute of Chemical Organic Technology, ul. Pulaskiego 10, 70-322 Szczecin, \\ Poland, e-mail: psa_czech@wp.pl
}

\begin{abstract}
The present paper discloses a novel photoreactive solvent-free acrylic pressure-sensitive adhesive (PSA) systems, especially suitable for the so much adhesive film applications as the double-sided, single-sided or carrier-free technical tapes, self-adhesive labels, protective films, marking and sign films and wide range of medical products. The novel photoreactive solvent-free pressure-sensitive adhesives contain no volatile organic compounds (residue monomers or organic solvent) and comply with the environment and legislation. The synthesis of this new type of acrylic PSA is conducted in common practice by solvent polymerisation. After the organic solvent are removed, there remains a non-volatile, solvent-free highly viscous material, which can be processed on a hot-melt coating machine at the temperatures of about 100 to $140^{\circ} \mathrm{C}$.
\end{abstract}

Keywords: polymerization, unsaturated photoinitiator, organic solvent, acrylic PSA, devolatilizing of solvent.

Presented at VII Conference Wasteless Technologies and Waste Management in Chemical Industry and Agriculture, Międzyzdroje, 12 - 15 June, 2007.

\section{INTRODUCTION}

Solvent-free pressure-sensitive adhesives potentially offer significant economic and environmental advantages over crosslinkable solvent systems. They are the compositions that combine the properties of solvent-free hot melt adhesives with the properties of pressure-sensitiveadhesives ${ }^{1}$. The hot melts are solids at room temperature, melt upon the application of heat, and regain their solid form on cooling. The PSA are aggressive and permanently tacky at room temperature, and adhere to surfaces by the application of light finger pressure ${ }^{2}$. The combination of these properties provide compositions that are melts at elevated temperatures and cool to form a permanently tacky solid coating that adheres to contact. These PSA are most commonly used applied to various substrates, such as paper, cloth, metal, and plastic films, which are then converted into tapes and labels for use in the packaging industry, particularly in marking, sealing and bonding applications, or for use in the health and pharmaceutical industry, particularly in bandages or transdermal drug delivery systems ${ }^{3}$.

A good workable hot melt PSA must exhibit high cohesive strength at room temperature and later after crosslinking at higher temperatures, low shrinkage on substrates, retention of pressure-sensitive properties during storage and use, and a relatively fluid viscosity at commonly employed application temperatures of 100 to $140^{\circ} \mathrm{C}$, Although very low molecular weight will yield a hot melt with sufficient fluidity, the resulting adhesives lack cohesive strength. High molecular weight polymers give better cohesive strength, but are too viscous at the common application temperatures to be easily coatable on substrates ${ }^{4}$.

To circumvent these problems, low molecular weight polymers have been made with unsaturated copolymerizable photoinitiators on the side chains. The photoreactive polymers, especially acrylic PSA, is than crosslinked by UV irradiation to provide sufficient cohesion and tack $^{5-7}$.
An outsider on this range of hot melts are $100 \%$-systems based on acrylics. Strictly speaking, the term ,acrylic hot melt" is misleading for this type of adhesives. Since this name does not stand for the well-known hot melt adhesives but for solvent-free PSA which can be melt coated. So, acrylic hot melts are the ecologically beneficial alternative to the common solvent-borne acrylic adhesives ${ }^{8}$.

The production of this new type of acrylic PSA is conducted in common industrially practice by solvent polymerisation. For some new special acrylic hot melts the polymerisation process is started at higher monomer concentrations. In view of the future degassing process, mixture of different solvents are being avoided. At the end of the polymerisation step, the polymer solution shows a polymer content of more than $50 \mathrm{wt} . \%$ (Tab. 1).

Table 1. Solvent-borne polymerisation processes

\begin{tabular}{|l|c|c|}
\hline Polymerisation process & old & new \\
\hline Starting concentration [wt.\%] & 50 to 60 & 60 to 80 \\
\hline Solvent system & $\begin{array}{c}\text { acetone, ethyl } \\
\text { acetate }\end{array}$ & ethyl acetate \\
\hline Final polymer content [wt.\%] & 30 to 50 & 50 to 60 \\
\hline
\end{tabular}

This means that in this first production step a reduction of about $50 \mathrm{wt} . \%$ of the solvent is possible. The fact that this beforehand eliminated solvent does not have to be removed during the following degassing process leads to decreased production costs and reduced ecological damage.

The various methods of degassing solvent-borne acrylic polymers solutions describe the following three processes: in a tunnel dryer, in a batch kneader and degassing in the reactor (Tab. 2).

Table 2. Volatile organic compound (VOC) concentration after degassing ${ }^{9}$

\begin{tabular}{|c|c|c|c|}
\hline Devolatilizing & $\begin{array}{c}\text { Tunnel } \\
\text { Dryer }\end{array}$ & $\begin{array}{c}\text { Batch } \\
\text { Kneader }\end{array}$ & $\begin{array}{c}\text { Polymerisation } \\
\text { Reactor }\end{array}$ \\
\hline VOC [wt.\%] & 2 to 3 & 1.5 to 2 & under 0.3 \\
\hline
\end{tabular}


At the moment, the degassing in the reactor after the polymerisation process seems to be a practicable way to produce acrylic hot melts from solvent-borne systems. During the degassing process viscosity will increase so that special reactor designs and sufficient heat input is necessary. However, the thermal stability of the acrylic PSA is an essential point of concern in this case. In the future further possibilities have to be tested because all present processes are not optimised with respect to the fact that acrylic polymers require special conditions during the devolitilizing step.

With the devolitilizing process the production of the acrylic hot melt PSA is finished. Solvent recovery permits an almost completely closed solvent circulation. All further production steps can now be carried out solvent-free.

The synthesised acrylic solvent-free PSA are crosslinked by the use of UV radiation. New developments are dealing with UV crosslinking and no backing problems are to be reported. A very important factor of economic interest are the lower equipment coast. UV crosslinking, however, is mostly limited to thin PSA layers ${ }^{\mathbf{1 0}}$.

\section{THE GOAL OF THIS WORK}

The following work was study the influence of significant steps in the UV technology of photoreactive solventfree acrylic PSA such as solvent-borne synthesis in ethyl acetate of photoreactive acrylic PSA, the degassing process under vacuum, using of the recovered solvent ethyl acetate for the new synthesis again, UV crosslinking of coated PSA layers and investigation of the main layers properties as tack, adhesion, cohesion and shrinkage.

\section{EXPERIMENTAL}

The investigated acrylic PSA ware synthesised by the use of 2-ethylhexyl acrylate (2-EHA) butyl acrylate (BA), methyl acrylate (MA), acrylic acid (AA) and unsaturated photoinitiator 4-acryloyloxy benzophenone (ABP) by polymerisation in ethyl acetate with the solid content of $60 \mathrm{wt} . \%$, AIBN-concentration of $0.1 \mathrm{wt} . \%$, dosage time of $2 \mathrm{~h}$ and the post-reaction time of $5 \mathrm{~h}$.

The mentioned acrylic monomers and ethyl acetate were purchased from BASF (Germany), 2,2'-azodiisobutyronitrile (AIBN) was available from Degussa (Germany) and the unsaturated photoinitiator ABP by ChemCycle (Germany).

The synthesised photoreactive solvent-free acrylic PSA were liberated from ethyl acetate and residue monomers, and after coating with four thickness of 30, 60, 90 and 120 $\mathrm{g} / \mathrm{m}^{2}$ coat weight on polyester film, crosslinked using a ultraviolet light lamp U 350-M-I-DL from IST Company.

The recovered ethyl acetate was used for the synthesis of solvent-borne acrylic PSA with the same starting composition again. After the polymerization after the removal of volatile organic compound, the obtained photoreactive acrylic PSA as self-adhesive layer was crosslinked with UV radiationn

The influence of the UV dose of tack, adhesion, cohesion and shrinkage was tested. The three first properties were determined by standard A.F.E.R.A. (Association des Fabricants Europeens de Rubans Auto-Adhesifs) procedures. Exact details can be found in AFERA 4015 (tack),
AFERA 4001 (peel adhesion) and AFERA 4012 (shear strength).

\section{RESULTS AND DISCUSSION}

\section{Influence of $A A$ and $A B P$ content on viscosity of photoreactive solvent-borne acrylic PSA.}

The aim of this chapter was to examine the influence of very important monomers such as acrylic acid and unsaturated photoinitiator 4-acryloyloxy benzophenone on viscosity effect of solvent-borne acrylic pressure-sensitive adhesives.

The viscosity $\eta$ of synthesised solvent-borne acrylic PSA, measured with a Rheomat RM 189 from Rheometric Scientific with spindle No 3 at $23^{\circ} \mathrm{C}$, versus AA and ABP concentration is presented in Tab. 3 and Figs. $1-2$.

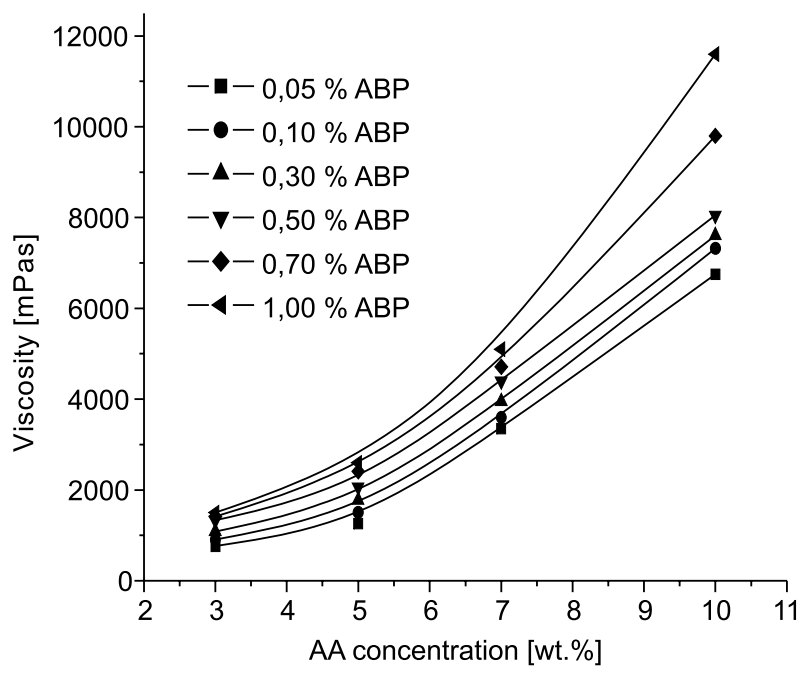

Figure 1. The effect of acrylic acid amount on the PSA viscosity

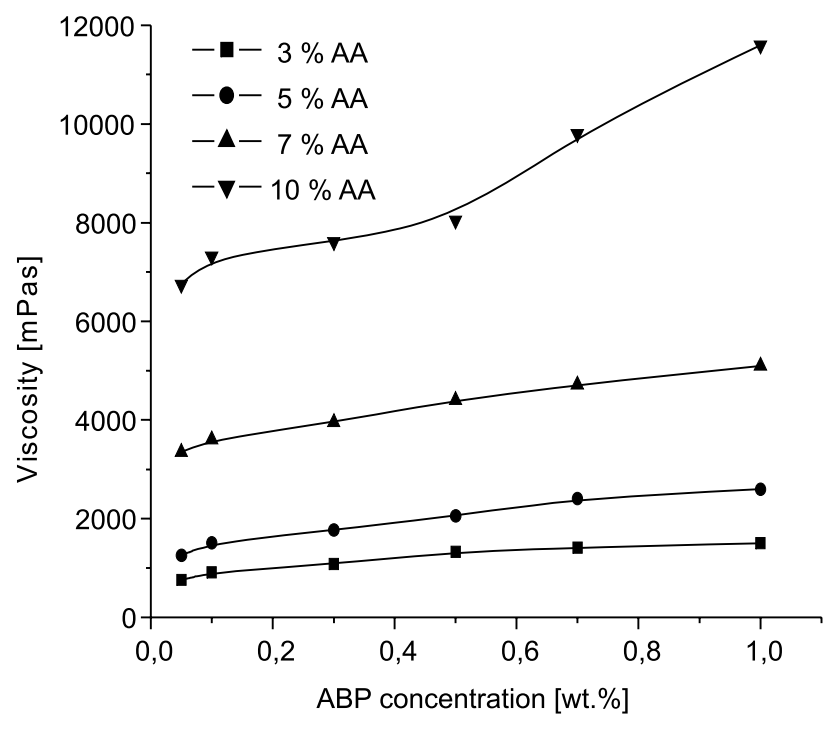

Figure 2. The effect of 4-acryloyloxy benzophenone amount on the PSA visco

The mentioned in Tab. 3 results demonstrate that the increase of acrylic acid level increases the viscosity of photoreactive solvent-borne acrylic PSA. In summary, the greatest viscosity of synthesized photoreactive acrylic PSA was registered for $10.0 \mathrm{wt} . \%$ acrylic acid and $1.0 \mathrm{wt} . \%$ of unsaturated photoinitiator ABP (Fig. 1). 
Table 3. Solvent-borne acrylic PSA containing diverse amounts of AA and ABP

\begin{tabular}{|c|c|c|c|c|c|c|}
\hline \multirow{2}{*}{$\begin{array}{c}\text { Acrylic } \\
\text { PSA No }\end{array}$} & \multicolumn{5}{|c|}{ Concentration of monomers [wt.\%] } & \multirow{2}{*}{$\begin{array}{c}\eta_{60 \text { wt.\% }} \\
{[\mathrm{mPa} \cdot \mathrm{s}]}\end{array}$} \\
\hline & 2-EHA & BA & MA & $\overline{A A}$ & ABP & \\
\hline 1 & 4395 & 330 & $\begin{array}{ll}200 \\
\end{array}$ & 30 & 005 & 760 \\
\hline 2 & 43.90 & 33.0 & 20.0 & 3.0 & 0.10 & 910 \\
\hline 3 & 43.70 & 33.0 & 20.0 & 3.0 & 0.30 & 1080 \\
\hline 4 & 43.50 & 33.0 & 20.0 & 3.0 & 0.50 & 1330 \\
\hline 5 & 43.30 & 33.0 & 20.0 & 3.0 & 0.70 & 1410 \\
\hline 6 & 43.00 & 33.0 & 20.0 & 3.0 & 1.00 & 1500 \\
\hline & & & & & & \\
\hline 7 & 41.95 & 33.0 & 20.0 & 5.0 & 0.05 & 1260 \\
\hline 8 & 41.90 & 33.0 & 20.0 & 5.0 & 0.10 & 1510 \\
\hline 9 & 41.70 & 33.0 & 20.0 & 5.0 & 0.30 & 1770 \\
\hline 10 & 41.50 & 33.0 & 20.0 & 5.0 & 0.50 & 2060 \\
\hline 11 & 41.30 & 33.0 & 20.0 & 5.0 & 0.70 & 2410 \\
\hline 12 & 41.00 & 33.0 & 20.0 & 5.0 & 1.00 & 2600 \\
\hline 13 & 3995 & 330 & 200 & 70 & 005 & 3350 \\
\hline 14 & 39.90 & 33.0 & 20.0 & 7.0 & 0.10 & 3600 \\
\hline 15 & 39.70 & 33.0 & 20.0 & 7.0 & 0.30 & 3950 \\
\hline 16 & 39.50 & 33.0 & 20.0 & 7.0 & 0.50 & 4400 \\
\hline 17 & 39.30 & 33.0 & 20.0 & 7.0 & 0.70 & 4710 \\
\hline 18 & 39.00 & 33.0 & 20.0 & 7.0 & 1.00 & 5100 \\
\hline 19 & 36.95 & 33.0 & 20.0 & 100 & 005 & 6750 \\
\hline 20 & 36.90 & 33.0 & 20.0 & 10.0 & 0.10 & 7320 \\
\hline 21 & 36.70 & 33.0 & 20.0 & 10.0 & 0.30 & 7610 \\
\hline 22 & 36.50 & 33.0 & 20.0 & 10.0 & 0.50 & 8050 \\
\hline 23 & 36.30 & 33.0 & 20.0 & 10.0 & 0.70 & 9800 \\
\hline 24 & 36.00 & 33.0 & 20.0 & 10.0 & 1.00 & 11600 \\
\hline
\end{tabular}

The received results shown that the increase of unsaturated photoinitiator ABP level increases a little bit the viscosity of investigated solvent-borne acrylic PSA. The greatest influence on the viscosity has been observed for PSA containing $10.0 \mathrm{wt} \%$ acrylic acid.

From the previous trials with the remove of polymerization medium under a vacuum resulted that the viscosity of solvent-borne acrylic PSA with $60 \mathrm{wt} . \%$ polymer greater than about $3000 \mathrm{mPa} \cdot \mathrm{s}$ at $20^{\circ} \mathrm{C}$ can lead to problems with the evaporation of volatile organic compound. Further investigations with suitable solvent-borne acrylic PSA $(\eta<3000 \mathrm{mPa} \cdot \mathrm{s})$ were conducted using 3.0 and 5.0 wt.\% acrylic acid (Tab. 1). Earlier commercial trials have shown that the best performances were observed for acrylic PSA containing $5.0 \mathrm{wt}$. AA and $0.5 \mathrm{wt} \%$ ABP.

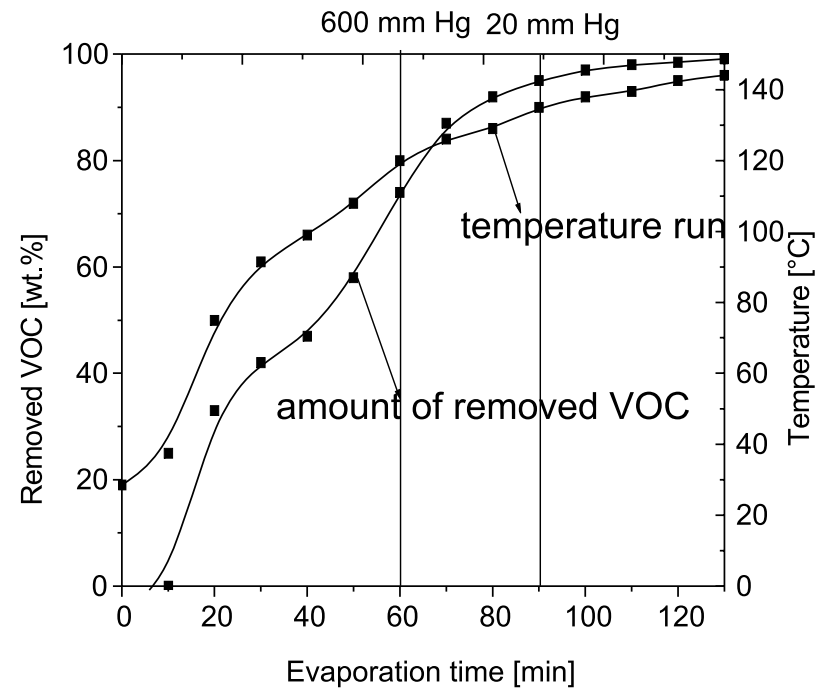

Figure 3. Temperature and the amount of the removed VOC during the evaporation time
Evaporation of volatile organic compounds from solventborne acrylic PSA

For further investigations the solvent-borne acrylic PSA 10 with viscosity of $2060 \mathrm{mPa} \cdot \mathrm{s}$ at $20^{\circ} \mathrm{C}$ was choose. The evaporation process was performed in two steps, which are illustrated in Fig. 3:

- first step: evaporation under atmospheric pressure at about $100-120^{\circ} \mathrm{C}$ $\mathrm{Hg}$

- second step: evaporation under vacuum 20 - $30 \mathrm{~mm}$

For industrially evaporation of VOC the using of polymerisation reactor seems to be a practicable way to produce of the solvent-free acrylic PSA from solvent-borne systems. The finished solvent-free acrylic PSA contained $0.3 \mathrm{wt} . \%$ of VOC. The due to evaporation received VOC were examinated by the use of gas chromatograph Varian CP-3800 (Tab. 4).

Table 4. GC analysis of VOC removed from photoreactive solvent-free acrylic PSA

\begin{tabular}{|c|c|c|}
\hline Composition [wt.-\%] & $\begin{array}{c}\text { VOC from solvent- } \\
\text { free acrylic PPSA }\end{array}$ & Removed solvent \\
\hline Ethyl acetate & 0 & 98.2 \\
\hline 2-EHA & 0.27 & 0.85 \\
\hline BA & 0.03 & 0.60 \\
\hline MA & 0 & 0.35 \\
\hline AA & 0 & 0 \\
\hline
\end{tabular}

Synthesis of solvent-borne photoreactive acrylic PSA using the removed solvent

The removed solvent containing $98.2 \mathrm{wt} . \%$ ethyl acetate and $1.8 \mathrm{wt} . \%$ residue monomers: $0.85 \%$ 2-EHA, $0.6 \mathrm{wt} . \%$ BA and $0.35 \%$ MA permits an almost completely closed solvent circulation. The new synthesised acrylic PSA 25 contains $5.0 \mathrm{wt} \%$ AA and $0.5 \mathrm{wt} \% \%$ ABP, analogical to acrylic PSA 10, shows a viscosity of $2110 \mathrm{mPa} \cdot \mathrm{s}$ at 60 wt. $\%$ polymers. 
Influence of the UV dose of the investigated properties of both synthesised acrylic PSA

The synthesised acrylic PSA 10 and PSA 25 were, after evaporation of $\mathrm{VOC}$, coated at $140^{\circ} \mathrm{C}$ with diverse coat weights of $30,60,90$ and $120 \mathrm{~g} / \mathrm{m}^{2}$ on the polyester film and crosslinked with UV radiation between 100 and 1000 $\mathrm{mJ} / \mathrm{cm}^{2} \mathrm{UV}$ dose. The greatest attention was dedicated the tack (Fig. 4), adhesion (Fig. 5), cohesion (Fig. 6) and shrinkage (Fig. 7) according the AFERA.

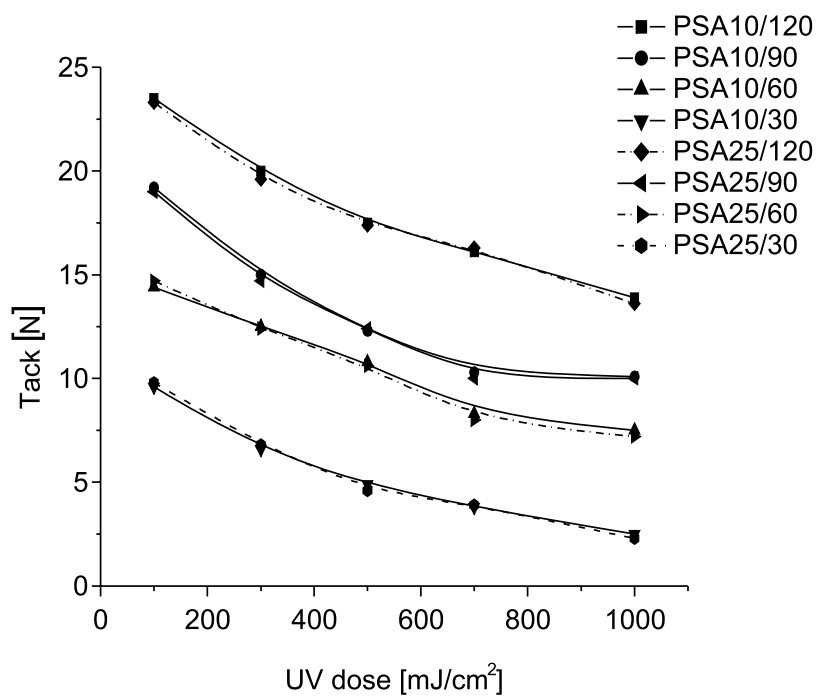

Figure 4. Tack of the UV crosslinked PSA synthesized in ethyl acetate and in the removed solvent

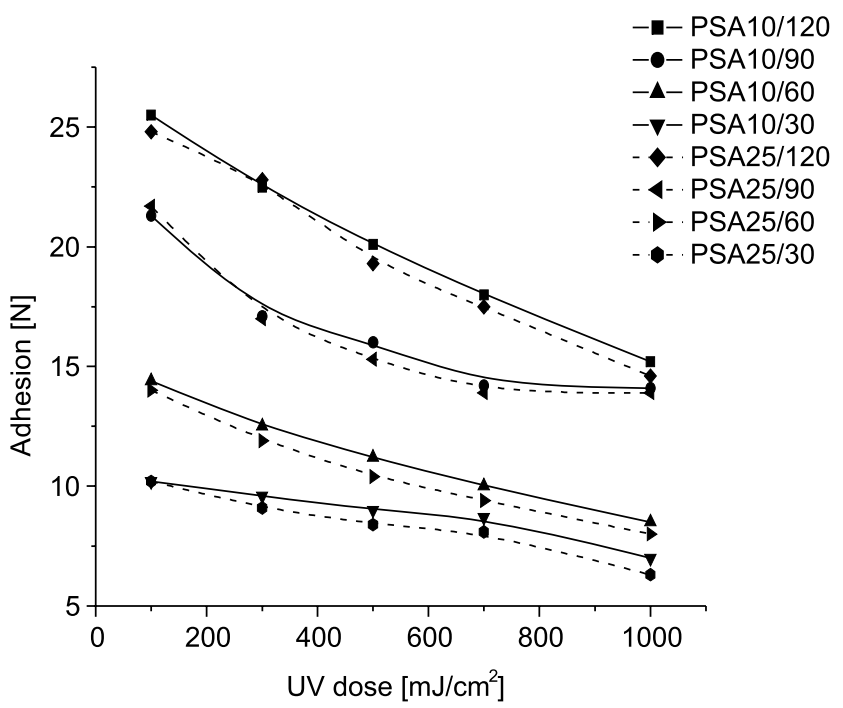

Figure 5. Adhesion of the UV crosslinked PSA synthesized in ethyl acetate and in the removed VOC

The best tack and peel adhesion values by application of photoreactive solvent-free acrylics PSA 10 and PSA 25 were observed from a UV dose of $100 \mathrm{~mJ} / \mathrm{cm}^{2}$ and for a thick layer of $120 \mathrm{~g} / \mathrm{m}^{2}$. This is comprehensible because the adhesive properties as tack and adhesion are very high for relatively thick layers and short UV crosslinking times, and a little UV doses. As it seems from the Figs. 4-5 the increasing of the UV radiation doses leads clearly to deterioration of tack and adhesion. In the practice no significant differences in tack and adhesion between the acrylic PSA 10 and acrylic PSA 25 were observed.

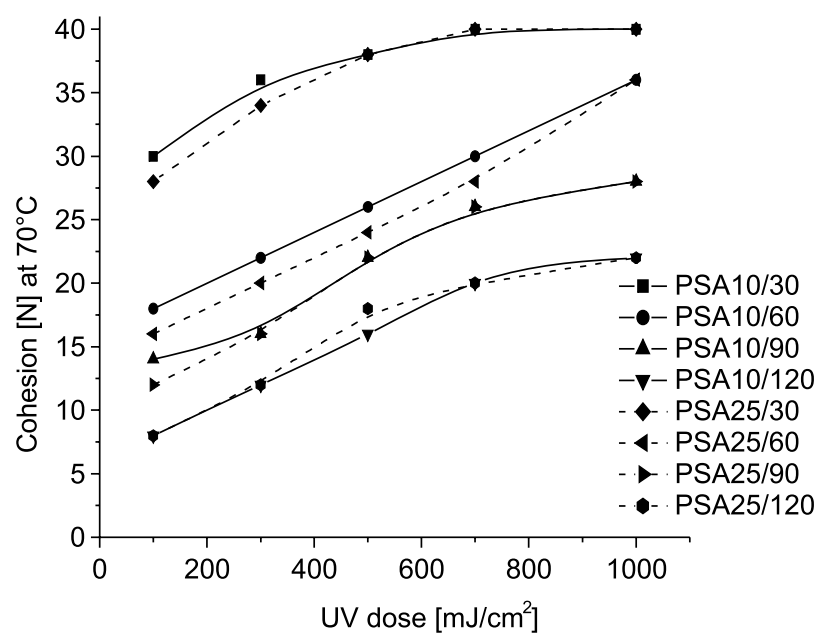

Figure 6. Cohesion of the UV crosslinked PSA synthesized in ethyl acetate and in the removed VOC

As shown in Fig. 6, the increase of UV dose from 100 to $1000 \mathrm{~mJ} / \mathrm{cm}^{2}$ is sufficient to obtain an adequate improving in cohesion of crosslinked photoreactive acrylic PSA at $70^{\circ} \mathrm{C}$.

The relatively high cohesion of $40 \mathrm{~N}$ was measured for $30 \mathrm{~g} / \mathrm{m}^{2}$ thick layers.

The target of this investigation was the development of photoreactive solvent-free acrylic PSA for PVC sign and marking films with high performance and low shrinkage. In this case, the greatest attention was attached to the shrinkage parameter. With PSA shrinkage greater than acceptable level $0.3 \%$ other evaluated PSAs properties were neglected.

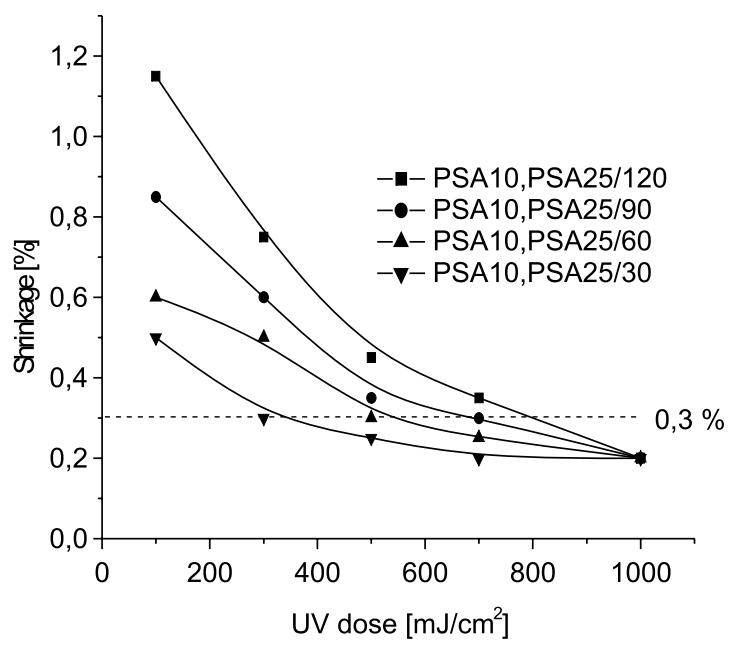

Figure 7. Shrinkage of the UV crosslinked PSA synthesized in ethyl acetate and in the removed solvent

As expected, the increase of the UV dose corresponds with the decrease of shrinkage of acrylic PSA. By using of pfotoreactive solvent-free acrylic PSA 10 in comparison to acrylic PSA 25 the exactly same shrinkage resistance run and shrinkage values were observed. For this reason a little UV dose between 100 and $500 \mathrm{~mJ} / \mathrm{cm}^{2}$ in UV crosslinking technology is becoming more and more replaced by greater UV dose of $1000 \mathrm{~mJ} / \mathrm{cm}^{2}$. Above this level of UV dose the shrinkage values of $0.2 \%$ were very low and identical for both investigated acrylic PSA. 
Prospects for synthesis of photoreactive acrylic PSA in recovered system

Photoreactive solvent-free acrylic pressure-sensitive adhesives will play a major role in the development and production of new generation of self-adhesive notes, paper and foil labels, double-sided tapes, carrier-free tapes, protective foils, self-adhesive bioelectrodes and medical tapes. The syntheses of those acrylic PSA can be conducted in the recovered organic solvent, in this case ethyl acetate. The incorporation of recovered organic solvent system into PSA technology is very important, among the other things with regard to the economic aspect, for environment protection, and manufacturing of ecological products.

\section{LITERATURE CITED}

(1) Czech Z.: Crosslinking of acrylic PSA, Published by Szczecin University of Technology, Szczecin, 1999 (ISBN 8387423-18-1).

(2) Chandran M.: EP 0608 891, National Starch and Chemical, 1994.

(3) Kurzawa R., Czech Z.: Ginekologia po dyplomie, wydanie specjalne, styczeń, 2007, 1 - 5 .

(4) Benedek I.: Developments in Pressure-Sensitive Prod-

ucts, Edited by Taylor \& Francis a CRC Press Book, 2006.

(5) Czech Z., Drzycimska A., Klementowska P.: European Coating Journal, 2007, 2, $26-30$.

(6) Czech Z.: DE 19501 24, Lohmann, 1995.

(7) Czech Z.: DE 19501 25, Lohmann, 1995.

(8) Auchter G.: Adhäsion, 1993, $1-2,14-20$.

(9) Czech Z.: Adhäsion, 1996, 9, 24 - 29.

(10) Shiaonung S.: US Patent 5,252,662, Avery Dennison Corporation, 1993. 